5. Appelbaum A, Kirklin JW, Pacifico AD, Bargeron LM. The surgical treatment of total anomalous pulmonary venous connection. Isr J Med Sci 1975;11:89-96.

\section{Innominate artery pseudoaneurysm presenting as a widened mediastinum}

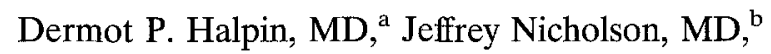

William S. Blakemore, MD, ${ }^{\mathrm{a}}$ and

John L. Harlan, MD, ${ }^{c}$ Birmingham, Ala.

Few cases of isolated innominate artery injury have been reported in the literature. Reported here is a successfully managed case of a false aneurysm of the innominate artery after blunt trauma.

A 23-year-old man was admitted after a motor vehicle accident. On admission he was in hemodynamically stable condition. Examination demonstrated a seat belt friction burn over the left clavicle. Upper extremity pulses were equal bilaterally. A chest roentgenogram revealed a grossly widened superior mediastinum, bilateral apical capping, and obscuration of the aortic knob. An oblique fracture of the left first rib was also noted (Fig. 1). Contrast-enhanced computed axial tomography revealed a normal aortic arch and aortic isthmus. There was no

From the Department of Surgery, ${ }^{a}$ Department of Radiology, Cardio-Thoracic Surgeons, P.C., Baptist Medical Centers, Birmingham, AL 35213-1984.

J Thorac Cardiovasc Surg 1995;109:390-1

Copyright (C) 1995 by Mosby-Year Book, Inc.

$0022-5223 / 95 \$ 3.00+0 \quad \mathbf{1 2 / 8 / 5 6 7 0 5}$ evidence of a transected aorta. Because of a persistently widened superior mediastinum, an arch aortogram was obtained several days later, which demonstrated a false aneurysm of the innominate artery at its origin (Fig. 2).

At operation, a 3 by $3 \mathrm{~cm}$ aneurysm of the innominate artery was found with a posterior intimal tear. Proximal control of the innominate artery was achieved intrapericardially. Distal control was obtained at the bifurcation of the innominate artery. Heparin was not used. After closure of the origin of the innominate artery with pledgetsupported polypropylene sutures, an aorta-innominate artery bypass with a $10 \mathrm{~mm}$ Dacron graft was performed with continuous electroencephalographic (EEG) monitoring.

The patient was discharged 4 days later. Currently the patient has no neurologic symptoms and has equal blood pressure in both arms.

Of 51 reported thoracic vascular injuries in a recent series, only one case of isolated trauma to the innominate artery was recorded. ${ }^{1}$ Blunt trauma of the thorax most frequently produces thoracic aortic transection (45\%) distal to the left subclavian artery.

Radiologic clues to the diagnosis of thoracic vascular injury include widening $(>8 \mathrm{~cm})$ of the superior mediastinum, apical pleural capping, obscuration of the aortic knob, and a fractured first rib; all were present in our patient. Other signs include depression of the left main bronchus more than 140 degrees from the trachea, loss of aortic knob contour, and deviation of the nasogastric tube in the esophagus away from the midline.

In a hemodynamically stable patient, arteriography is mandatory. ${ }^{2}$ The use of computed tomography and magnetic resonance imaging is currently not recommended. ${ }^{3}$ The primary objection to computed tomography as a screening tool is that in most instances, including this case, it provides only circumstantial evidence of an aortic injury. Transesophageal echocardiography has recently been de-

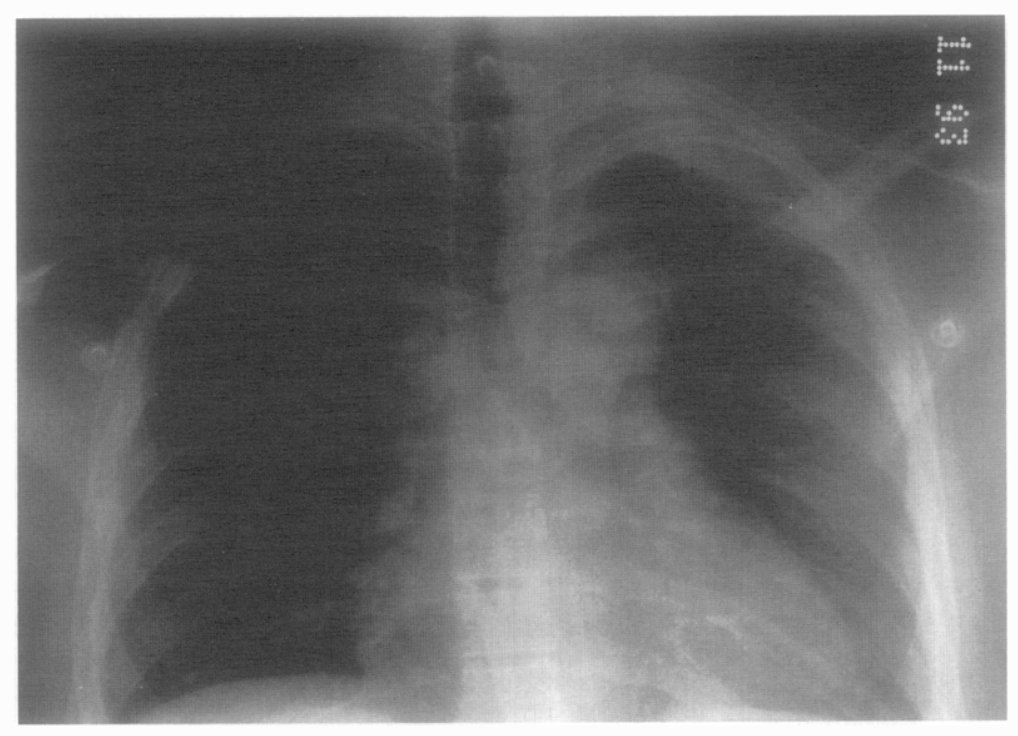

Fig. 1. Chest roentgenogram showing widened mediastinum, bilateral pleural capping, fractured left first rib, and obscuration of the aortic knob. 


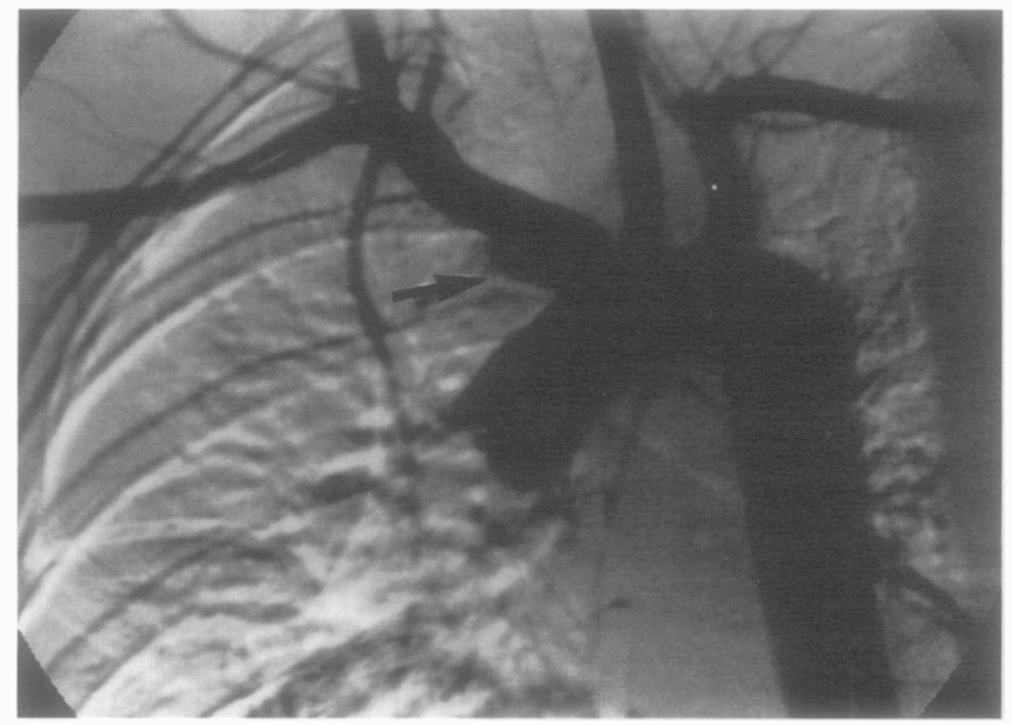

Fig. 2. Subtraction angiogram showing a pseudoaneurysm of the innominate artery (arrow).

scribed in evaluating blunt thoracic trauma. ${ }^{4}$ It can be performed safely and rapidly at the bedside, requires less time than aortography, and does not require contrast dyes. One report quoted sensitivity and specificity at $100 \%$ for recognizing traumatic aortic injury. ${ }^{5}$ Transesophageal echocardiography can differentiate traumatic aortic rupture from ductus diverticulum, which can give a false positive aortogram. Its sensitivity in recognizing trauma to the innominate artery is unknown.

A recent article in this Journal discussed the use of a vascular pericardial flap placed between the Dacron graft and the innominate vein to protect the vein from the oscillating movement of the graft. ${ }^{6}$ We believe this flap is necessary only when the graft is placed anterior to the innominate vein. If the graft is placed in its normal anatomic position (posterior to the vein), the oscillating movement of the graft should not produce a sawing motion against the vein. Delay in diagnosis may lead to permanent injury or disability in the hand from distal small vessel thrombosis or to neurologic sequelae caused by ipsilateral carotid occlusion. Further delay can lead to exsanguination after delayed rupture. Cardiopulmonary bypass and heparinization are not necessary in achieving successful repair.

In summary, blunt injury involving the innominate artery is rare. Those patients who survive to reach the hospital may have minimal external signs of trauma. Surgical awareness, clinical suspicion, and aortography are essential in diagnosis.

\section{REFERENCES}

1. Weaver FA, Suda RW, Stiles GM, Yellin AE. Injuries to the ascending aortic arch and great vessels. Surg Gynecol Obstet 1989;169:27-31.

2. Mattox KL. Thoracic vascular trauma. J Vasc Surg 1988;7:725-9.

3. Oudkerk M, Overbosch E, Dee P. CT recognition of acute aortic dissection. AJR Am J Roentgenol 1983; 141:671-6.

4. Brooks SW, Young JC, Cmolik BL, et al. The use of transesophageal echocardiography in the evaluation of chest trauma. J Trauma 1992;32:761-5.

5. Kearney PA, Smith DW, Johnson SB, Barker DE, Smith MD, Sapin PM. Use of transesophageal echocardiography in the evaluation of traumatic aortic injury. J Trauma 1993;34:696-703.

6. Asimacopoulus PJ, Camel JE, Iliopoulos DC, Reardon MJ. Blunt injury of the innominate artery: use of vascular pericardial flap. J THORAC CARDIOVASC SURG 1993;105:764-5.

\section{A simplified technique for selective jugular vein cannulation}

Akio Matsuura, MD, Masaru Sawasaki, MD, Kenzo Yasuura, MD, Takashi Maseki, MD, Toshihiko Ichihara, MD, Toshiaki Ito, MD, Ken Miyahara, MD, Hiroshi Okamoto, MD, and Toshio Abe, MD, Nagoya, Japan

Hypothermic retrograde cerebral perfusion has been a successful method of cerebral protection during aortic

From the Department of Thoracic Surgery, Nagoya University School of Medicine, Tsurumaichou-65, Shouwa-ku, Nagoya, Japan.

J Thorac CARdIovasc SuRg 1995;109:391 3

Copyright (C) 1995 by Mosby-Year Book, Inc. $0022-5223 / 95 \$ 3.00+0 \quad \mathbf{1 2 / 8 / 5 7 7 7 9}$ 